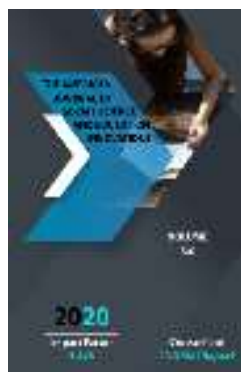

\title{
The Semantic And Functional Characteristics Of Syntactic Stylistic Devices In The Example Of Repetition
}

\author{
Munira Makhamadievna Atamuratova \\ 2-Course Master Of Foreign Language And Literature Department, Faculty Of Philology, \\ Termez State University
}

Journal Website: http://usajournalshub.c om/index,php/tajssei

Copyright: Original content from this work may be used under the terms of the creative commons attributes 4.0 licence.

\section{ABSTRACT}

This article aims to indicate the importance of syntactic stylistic devices mainly repetition in textual formulation that is based on the characteristics of the oral form of speech and syntactic stylistic devices which is expressed the structural meanings of the syntactic stylistic devices. In the aspects of this problem, it is important to analyze the role of syntactic stylistic devices in the formation of functional styles of the language, to justify the importance of syntactic stylistic devices in the presenting the main logic and contextual meanings in the literary texts. As analyzing any kind of literary text syntactic stylistic devices, that is repetition, chiasmus, stylistic inversion, gradation, ellipsis, antithesis, parallel construction, detached construction and enumeration have the greatest impact. However, according to results of analyzing, repetition is one of the widely used within these syntactic stylistic devices by contrast other models of speech.

\section{KEYWORDS}

Repetition, syntactic, stylistic devices, literary text, scattered, thematic, functional.

\section{INTRODUCTION}

To begin with, it is worth noting that the results of fundamental studies in linguistics in recent years show that there is still much work which has to be done. In recent years, a number of research work have been carried out in the field of cognitive linguistics, comparative linguistics, pragmalinguistics and certain progress has been made. It is worth mentioning here that many stylistic studies were carried out by I. Arnold, I.R.Galperin, as well as scholars from Uzbek linguists U.D.Ashurova, M.R.Galieva and J.Jumabaeva. 
This work aims to illuminate the importance of stylistic device, mainly repetition in textual formulation that is based on the characteristics of the oral form of speech and the stylistic devices which is expressed the structural meanings of the syntactic stylistic devices. In the next parts of the article the abbreviated form of SDs is used for syntactic stylistic devices. In the process of studying the work in theoretical way, it is clarified that it is important to analyze the role of syntactic SDs in the formation of functional styles of the language, to justify the importance of it in presenting the main logic and contextual meanings in the literary texts. One of the main object of studying the role syntactic SDs in the interrelation of the text and different structural meaning and the full disclosure of the meaning of literary texts and contextual meaning. We know, analyzing the syntactic stylistic means is a significant in establishing close interrelationship in stylistics. Interrelation of the text and various content meanings and the role of syntactic SDs in the full disclosure of literary text and contextual meanings to simplify concepts in the study of theory.

\section{THE MAIN FINDINGS AND RESULTS}

Stylistic devices are purposeful combination of expressive and figurative means of different language levels (phonetic, graphic, grammatical, lexical and textual) with a dynamic change of their functions: amplification, displacement or generalization. $[1$, p.10].

Expressive means are set of morphological, syntactical, world-building of forms language, which may be used for emotive enhancement of speech and logical accentuating. Expressive means are part of speech. They are fixed in dictionaries, grammar manuals, textbooks and are used in ready-made form [1, p.10].

All syntactic SDs of English can be divided into 3 groups:

1. Syntactic SDs based on the reduction of sentence model by deliberately omission of some elements in the sentence. To this group belong ellipsis, aposiopesis and asyndeton.

2. Syntactic SDs which are based on the extension of sentence model by adding some elements or they deliberate repetition. To this group includes repetition, enumeration, chiasmus and polysyndeton.

3. Syntactic SDs based on the change of grammatical fixed word order in sentence or deliberate separating some part of sentence. Into this group belong such figures like inversion, detachment, parallel construction and rhetoric question [2, pp. 139-158].

Using of stylistic devices and expressive means often can be perceived as a kind of linguistic deviation. According to French linguist Joseph Vandries, artistic style is always a reaction against common language and it is an argot that has various forms. [3, p.251].

Syntactic SDs are those of expressive means that form a complete syntactic structure, which is considered their most common characteristic. Syntactic SDs are one of the syntactic-intonation methods that generate expression in the literary literature and perform a certain methodological function. Syntactic SDs are specific syntactic turnovers that help increase the emotionality of speech, which includes parallelism, repetition and its types, antithesis, stylistic inversion, ellipsis and gradation. [4, p.230]. Famous English scientist Alexander Ben said that figures of speech are 
some deviation in usual way of communication in order to amplify impressions. [5, p.8].

One of the most commonly used syntactic SDs in the literary language is repetition. Repetition is a SD that is used mostly to express extiment. Emotional speech is characterized by shortness, logic and repetition of certain points of view. Many discussions concerning repetition are led with the objective to find the answer. To begin with, "The New Fowler's Modern English Usage" explains that repetitions in ordinary grammatical structures can be accidental. Repetition can be undesirable if the same words are repeated too closely to each other. The improper usage is a frequently mentioned problem. For example, Preminger and Brogan believe that inappropriate use is grounded in its overuse by poets [6, p.1035]. McArthur reminds that formal writing ordinarily avoids repetition "for the sake of economy and in favor of a tradition of elegant variation." [7, p.862]. We can observe the repetition of certain words and in some cases word combinations in the spoken language. E.g. "She shricked loudly: "where is my baby? But where is my baby? I want to know where is my baby?" (A. Bennet.). In this sentence we can see that the phrase "where is my baby?" is repetition, however according to some opinions, it doesn't fulfilled a SD here. It simply expresses a certain excited state of the speaker. The excited speech always broken, fragmented illogical and that's why it is natural to use the repetition of words, phrases, word combinations and some parts of the sentences. Most of linguists have an opinion that repetition is not a SD if it indicates the excited states of mind of the speaker as we can observe in previous example. The scientific observers which follows to this idea, consider that repetition doesn't show emotional state but just concentrate on logical emphasis of the utterance. On the contrary, we are against this idea as we consider that repetition is one of the syntactic SD and have its origin in the emotive language. Describing logical emphasis in the sentences are really very crucial in case of repetition. By repeating certain words, word combinations, phrases or clauses, readers are reminded of their importance and is used them as key words, phrases, clauses or sentences of the text by writers.

As it has been contradicted above, repetitio ought to be considered as a SD when it is not only repeated for logical emphasis but also to indicate a speaker's emotional state.

Repetition is classified according to its structure and compositional design.

1. If the repeated words, word combinations or phrases come at the beginning of the sentences or clauses, it is called anaphora. E.g. "Ignorant of how soarnes had watched her, ignorant of Fleur's reckless desperation...- ignorant of all this everybody felt aggrieved ". ( Galsworthy).

Preminger and Brogan comment that anaphora is favored because its structure reinforces the meaning of words.

2. The opposite to anaphora is epiphora (or epistrophe) which "repeats words at the ends of clauses, lines or stanzas" [6, p. 73].

If the repeated unit is placed in the final of the phrases, sentences or clauses this type of words or word combinations is called epiphora. E.g. " The clerks rattle me. The wickets rattle me, the sights of money rattle me, everything rattles me". (S. Leacock). However, in this type of repetition, there has a merely various function, that is, it become a background against 
which the preceding statements become more prominent.

3. In some cases, a syntactical unit which is placed at the beginning, is repeated at the end and it is called frame repetition. This structural type of repetition mostly used in poetry and it is most effective in singling out paragraphs.

Our hands have met, but not our hearts;

Our hands will never meet again.

Friends, if we have ever been

Friends, we can't now remain:

I only know I loved you once, I only know I loved in vain.

Our hands have met, but not our hearts.

Our hands will never meet again.

(Thomas Hood)

4. The fourth model of repetition is anadiplosis. In this type of repetition an utterance words or phrases are repeated in the last also at the beginning of the next sentences or clauses. E.g. "All service ranks the same with God, With God whose puppets, best and worst, are we". ( Robert Browning). Anadiplosis serves to emphasis the most important parts of the sentences.

5. The next type of the repetition is chain repetition. In this compositional form of repetition linking device is repeated smoothly several times be developing logical reasoning in one utterance. E.g. "A smile would come into Mr.Pickwick's face: The smile extended into a laugh, a laugh into a roar, and the roar became general". ( Ch. Dickens).

6. The next type of repetition is called synonym repetition. In this form the repeated words word combinations or phrases come with not only the same words but also is repeated by means of various synonyms. E.g. "I nearly died! Honestly, I give you my word, I nearly passed away!”. (D. Parker).

All existing model of repetition have been briefly classified. But now we are going to illuminate a new type of repetition which was shown by analyzing the material under the investigation in Modern English. We call this type of repetition scattered and thematic repetition.

According to classification throughout the whole text a word, a phrase, a clause or a sentence is repeated several times. The aim of the scattered repetition is the same as of all other models of repetition but structurally this model doesn't correspond with any existing type of repetition. The fact that scattered repetition is shown everywhere in the text without any definite structure made us conclude with calling it scattered repetition. E.g. He opened his dry, cracked mouth; his mouth had been open for a long time, but he opened his mouth wider. He tried to say, weakly, "Posse”. ("The last Bullet" M. Kantor).

Another result of investigation is called thematic repetition. In this type of repetition, without any certain types of repetition, the theme of the text is repeated. Modern researchers indicate A. Coppard's short story "Tribute" as a good example of thematic repetition. E.g. The country paid them tribute, and therefore, as the Regents' wealth continued to flow in, they helped their country more and more; they even lent the tribute back to the country and received yet more tribute for that.

To sum up, Repetition may be often considered undesirable and showing carelessness. As a result, it is arguable whether repetition is useful or not. Generally, it is understood that 
repetition has negative effects but only when used inadequately or with carelessness. In connection, Aitcheson states: "Linguists are therefore faced with the paradox that repetition is widely used, yet widely avoided." [8, p.18]. Quirk contrasts that lexical recurrence is generally avoided as it may seem obtrusive. He also stresses that repetition is tolerated in legal language to escape misinterpretation. Nevertheless, repetition is commonly used in non-specialized texts to produce emphasis [9, p.144].

The question of repetition being positive or negative is not to be answered straightforwardly. H.W. Fowler and F.G. Fowler in their book “The King's English" summarize that "we have instances of repetition that are good in themselves; we have repetition that are neither particularly good nor particularly bad in them, but that offend simply by recurrence." [10, p.211]. To summarize these discussions, repetition may be perceived as useful but also as useless in many cases depending on the speaker's skillful usage. In modern English by analyzing materials, it can be said that besides from the existing model of repetition are investigated and singled out two new types of repetition that scattered and thematic repetition. Both new types of repetitions have the same emotional levels as others although both of them are less mentioned in the research works.

\section{REFERENCES}

1. Babelyuk O. A. (2011), Stylistic means and devices through the prism of linguistic synergetics, Bulletin of the Kiev National Linguistic University. Series: Philology, T. 14, No. 1, pp. 7-17.

2. Morokhovsky A., Vorobyova O., Likhosherst N., Timoshenko Z. (1984),
Stylistics of the English language, Kiev: The head publishing house of the publishing association "Vishcha shkola", 2415.

3. Vandries J. (2004), Language. Linguistic introduction to history, M.: Editorial URSS, $410 \mathrm{~s}$.

4. Shomaksudov A., Rasulov I., (1983), O'zbek tili Stilistikasi., Toshkent., $230 \mathrm{~s}$

5. Ben A. (1886), The Stylistics and Theory of Oral and Written Speech, K. Soldatenkova, M., 293 S.

6. Preminger, Brogan, (1993), The new Princeton Encyclopedia of Poetry and Poetics, Princeton, New Jersey Princeton university press, $\mathrm{p} 1035$.

7. McArthur Tom, (1992), The Oxford Companion to English Literature, Oxford University Press, p 862.

8. Aitchison, (1994), Words in the mind: An introduction to the mental lexicon, Oxford and New York: Basil Blackwell, 2nd edition, p 18.

9. Aitchison, (1994), Words in the mind: An introduction to the mental lexicon, Oxford and New York: Basil Blackwell, p 144.

10. Fowler H. W., Fowler F. G., (1922), The Kings English, Oxford at the Clarendon Press, p 211.

11. Galperin I., (1980), Stylistics, Moscow.

12. Арнольд И. В., (1981), Стилистика современного английского языка (стилистика декодирования). - Л.: Просвещение.

13. Панжиева Н.Н., (2017), Когнитивностилистическая парадигма оценочных номинаций лица в английском и узбекской языках. - Ташкент: Muharrir nashriyoti. 